\title{
CARACTERIZAÇÃO DE SINTOMAS DE CARÊNCIAS NUTRICIONAIS EM MUDAS DE PUPUNHEIRA CULTIVADAS EM SOLUÇÃO NUTRITIVA.
}

\author{
José Risonei Assis da SILVA*, Newton Paulo de Souza FALCÃO*
}

RESUMO - Os conhecimentos de nutrição mineral da pupunheira (Bactris gasipaes Kunth, Palmae) são relativamente escassos e incipientes, faltando dados consistentes sobre sua demanda nutricional desde a fase de viveiro até a fase de produção. Com o objetivo de caracterizar os sintomas de carências de macro e micronutrientes, e identificar os níveis analíticos associados às carências minerais em mudas de pupunheira, foi conduzido um ensaio em casa de vegetação, pertencente ao Instituto Nacional de Pesquisas da Amazônia, Manaus, AM. Plantas de pupunheira foram cultivadas em solução nutritiva, tendo como substrato areia lavada. Os tratamentos foram: completo e omissão individual de nitrogênio, fósforo, potássio, cálcio, magnésio, enxofre, ferro, boro, cobre, manganês, zinco e molibdênio. $O$ delineamento experimental foi inteiramente casualizado com treze tratamentos e quatro repetições. As deficiências dos nutrientes nas mudas de pupunheiras se traduziram por sintomas típicos e facilmente identificáveis, e os níveis analíticos de adequação e deficiência obtidos nas folhas foram: $\mathrm{N}\left(\mathrm{g} \mathrm{kg}^{-1}\right) 30.7$ - 10.1; $\mathrm{P}\left(\mathrm{g} \mathrm{kg}^{-1}\right) 3.4$ - 1.0; $\mathrm{K}\left(\mathrm{g} \mathrm{kg}^{-1}\right) 27.8$ - 4.7; $\mathrm{Ca}\left(\mathrm{g} \mathrm{kg}^{-1}\right) 12.7$ - 2.6; $\mathrm{Mg}\left(\mathrm{g} \mathrm{kg}^{-1}\right) 3.5$ - 0.9; Fe $\left(\mathrm{mg} \mathrm{kg}^{-1}\right) 175$ - 191; $\mathrm{Zn}(\mathrm{mg}$ $\left.\mathrm{kg}^{-1}\right) 33-41$.

Palavras-chave: Bactris gasipaes, composição mineral

Characterization of Symptoms of Nutritional Deficiencies in Peach Palm Cultivated in Nutrient Solution.

ABSTRACT - Information on peach palm (Bactris gasipaes Kunth, Palmae) mineral nutrition is scanty. This study was carried out in a greenhouse of the National Research Institute for Amazonia, Agronomy Department, to characterize the symptoms of nutrient deficiency and to identify the critical nutrient levels. Peach palm plants are cultivated in sand with 13 nutrient solutions: complete nutrient solution, minus nitrogen, phosphorus, potassium, calcium, magnesium, sulphur, iron, boron, copper, manganese, zinc, and molybdenum. The experimental design was completely randomized with 13 treatments and four replications. Nutrient deficiencies in the peach palm seedlings were easy identified and the analytical levels of adequacy and deficiency in the leaves were: $\mathrm{N}\left(\mathrm{g} \mathrm{kg}^{-1}\right) 30.7$ - 10.1; $\mathrm{P}\left(\mathrm{g} \mathrm{kg}^{-1}\right) 3.4$ - 1.0; $\mathrm{K}\left(\mathrm{g} \mathrm{kg}^{-1}\right) 27.8$ - 4.7; $\mathrm{Ca}\left(\mathrm{g} \mathrm{kg}^{-1}\right) 12.7$ 2.6; $\mathrm{Mg}\left(\mathrm{g} \mathrm{kg}^{-1}\right) 3.5$ - 0.9; $\mathrm{Fe}\left(\mathrm{mg} \mathrm{kg}^{-1}\right) 175$ - 191; $\mathrm{Zn}\left(\mathrm{mg} \mathrm{kg}^{-1}\right) 33$ - 41 .

Key-words: Bactris gasipaes, leaf nutrient content

\section{Introdução}

Na Amazônia pode-se encontrar uma grande variedade de frutíferas nativas com possibilidade de uso na agroindústria e com potencial importante para o desenvolvimento agrícola regional. A pupunheira (Bactris gasipaes Kunth, Palmae) é uma espécie que atualmente está tendo grande importância devido ao seu potencial alimentício e econômico (Clement \& Mora Urpi, 1987). De uma maneira geral, a pupunheira oferece dois produtos de grande importância econômica: a) palmito e b) fruto. Este último possui diversas finalidades (consumo direto como alimento, extração de óleo, farinha e ração animal) (Arkcoll \& Aguiar,

*Instituto Nacional de Pesquisas da Amazônia, INPA/CPCA, Cx. Postal 478, 69011-970 Manaus, AM, Brasil. e-mail: risonei@inpa.gov.br 
1984; Clement \& Mora Urpi, 1987).

A capacidade de produção da pupunheira em um bom sistema de cultivo ultrapassa as 25 toneladas de frutos por hectare e $2 \mathrm{t} \mathrm{ha}^{-1}$ de palmito, a qual poderia ser elevada através do melhoramento genético e com práticas agronômicas apropriadas (Mora Urpi, 1984). Estudos têm sido realizados no sentido de diminuir o período de formação de mudas de pupunheira, quer seja através de processos que aumentem a velocidade de germinação, ou pela utilização de substratos e adubações químicas e orgânicas que favoreçam o seu desenvolvimento. A utilização de substrato com baixo nível de fertilidade leva à formação de mudas com carências nutricionais, comprometendo o desenvolvimento tanto do sistema radicular, como da parte aérea. Segundo Lopes (1989), embora muitas vezes a diagnose visual não revele sintomas de carências nutricionais, quando se efetua a diagnose foliar observa-se teores muito baixos de alguns nutrientes, mostrando que a planta apresentava "fome escondida".

A diagnose visual consiste em comparar o aspecto da amostra com o de um padrão. Na maior parte dos casos compara-se o aspecto da folha. Se houver falta ou excesso de um elemento, isto será traduzido em anormalidades visíveis, as quais são típicas para o elemento em questão. A composição mineral da folha ou o teor dos elementos nela encontrado é conseqüência do efeito dos fatores que atuaram e, às vezes, interagiram até o momento em que o órgão foi colhido para análise (Malavolta et al., 1989).

A carência de cada elemento considerado essencial para o crescimento das plantas desencadeia determinados fenômenos bioquímicos dentro das plantas, os quais são externados por sintomas típicos (Epstein, 1975). Segundo Molina (1997), o diagnóstico de problemas nutricionais, mediante a observação de sintomas, tem grande importância prática porque permite tomar decisões rápidas no campo para a correção das deficiências. La Torraca et al. (1984), descrevendo o quadro sintomatológico das carências de macronutrientes e boro em mudas de pupunheira, observaram que os primeiros sintomas visuais nas plantas foram os de carência de enxofre, seguido do nitrogênio, cálcio, potássio, magnésio, fósforo e, finalmente, o boro.

A utilização de soluções nutritivas constitui importante técnica para a realização de estudos envolvendo aspectos associados à nutrição de plantas, tais como: eficiência de absorção e utilização de nutrientes; caracterização de sintomatologias de carências e excessos de nutrientes; estudos sobre aspectos histológicos, morfológicos e anatômicos de raízes submetidas a diferentes teores e relações entre nutrientes; translocação e compartimentalização de nutrientes nas plantas; interações - antagonismo e sinergismo - entre nutrientes, etc (Novais et al., 1991).

Os trabalhos sobre nutrição mineral da pupunheira são raros e 
incipientes, faltando dados consistentes sobre sua demanda nutricional, desde a fase de viveiro até a fase de produção. Tratando-se de uma cultura que tende a se expandir, tanto na região Norte como em outras regiões do país, os conhecimentos de nutrição mineral dessa espécie tornamse fundamentais, como base necessária para os programas de adubações e, consequentemente, o desenvolvimento sustentável da cultura.

O presente trabalho teve como objetivo caracterizar os sintomas de carências de macro e micronutrientes em mudas de pupunheira e identificar os níveis analíticos associados às carências minerais.

\section{Material e Métodos}

Foram utilizadas sementes de pupunheira (Bactris gasipaes Kunth, Palmae) oriundas de uma população de Yurimaguas, Peru. A semeadura foi efetuada em caixas de madeira, contendo como substrato serragem. Após a germinação, as plântulas permaneceram por, aproximadamente, dois meses nesse substrato quando foram repicadas para uma bandeja contendo como substrato areia lavada, onde permaneceram durante um mês, sendo irrigadas somente com água destilada. Por ocasião da repicagem, efetuou-se a remoção das sementes que ainda encontravam-se aderidas ao coleto das plântulas.

Posteriormente, as plântulas foram transplantadas para vasos de plástico contendo $5 \mathrm{~kg}$ de areia lavada. Os vasos foram pintados em sua superfície externa com tinta aluminol e, em sua porção superior, colocou-se uma tampa de isopor com pequeno orifício no centro para fixação da plântula. Esse procedimento foi utilizado para impedir a incidência interna de luz no substrato e, consequentemente, o desenvolvimento de algas.

As plantas passaram inicialmente por um período de adaptação e uniformização durante dois meses, sendo irrigadas diariamente por percolação dos vasos com solução nutritiva completa de $1 / 5$ de força iônica para posteriormente receber os tratamentos com 1 força (concentração de base normal).

O experimento foi conduzido em casa de vegetação, no Instituto Nacional de Pesquisas da Amazônia, Manaus, AM, em delineamento inteiramente casualizado, com treze tratamentos e quatro repetições. Cada parcela experimental foi representada por uma planta. Os tratamentos foram os seguintes: completo e omissão individual de nitrogênio, fósforo, potássio, cálcio, magnésio, enxofre, ferro, boro, cobre, manganês, zinco e molibdênio. As soluções nutritivas empregadas foram as de Sarruge (1975) e Jacobson (1951) (Tab. 1) .

As plantas foram irrigadas diariamente por percolação dos vasos, sendo as soluções nutritivas renovadas a cada 20 dias, até o quadro sintomatológico das carências nutricionais tornar-se evidente. A evolução dos sintomas de deficiência dos elementos nutrientes foram descritos desde o estágio inicial até tornarem-se bem definidos, procedendo-se então, a 
coleta das plantas.

O material colhido foi lavado e colocado para secar em estufa com circulação forçada de ar a $60-65^{\circ} \mathrm{C}$, até atingir peso constante. Posteriormente, efetuaram-se em laboratório as determinações dos teores de macro e micronutrientes nas folhas, de acordo com os métodos descritos por Sarruge \& Haag (1974).

\section{Resultados e Discucssão}

Sintomas de deficiência

\section{Nitrogênio}

As plantas cultivadas em solução nutritiva com omissão de nitrogênio ficaram pouco desenvolvidas. Após dois meses de uso da solução sem $\mathrm{N}$, observou-se clorose, inicialmente nas folhas mais velhas, seguida de necrose nas margens das folhas. Com o tempo, esta clorose tornou-se generalizada em toda a planta (Fig. 1). Os sintomas descritos concordam parcialmente com La Torraca et al. (1984), não se observando a manutenção da coloração verde, característica nas folhas mais novas, descritos por esses autores. Por se tratar de um elemento móvel dentro da planta, a redistribuição do nitrogênio foi bastante clara, uma vez que as folhas velhas foram as primeiras a apresentar o sintoma. Esta coloração

Tabela 1. Composição das soluções nutritivas, em $\mathrm{mL} \mathrm{L}^{-1}$, utilizadas em mudas de pupunheira para obtenção de deficiências de nutrientes.

\begin{tabular}{|c|c|c|c|c|c|c|c|c|c|c|c|c|c|}
\hline \multirow[b]{2}{*}{ Substância } & \multirow[b]{2}{*}{ Completo } & \multicolumn{7}{|c|}{ Omissão } & \multirow[b]{2}{*}{$-B$} & \multirow[b]{2}{*}{$-\mathrm{Cu}$} & \multirow[b]{2}{*}{$-M n$} & \multirow[b]{2}{*}{$-Z n$} & \multirow[b]{2}{*}{$-\mathrm{Mo}_{0}$} \\
\hline & & $-\mathrm{N}$ & $-P$ & $-K$ & $-\mathrm{Ca}$ & $-M g$ & $-S$ & $-\mathrm{Fe}$ & & & & & \\
\hline $\mathrm{KH}_{2} \mathrm{PO}_{4}-\mathrm{mol} \mathrm{L}^{-1}$ & 1 & 1 & & & 1 & 1 & 1 & 1 & 1 & 1 & 1 & 1 & 1 \\
\hline $\mathrm{KNO}_{3}-\mathrm{mol} \mathrm{L}^{-1}$ & 5 & & 5 & & 5 & 3 & 3 & 5 & 5 & 5 & 5 & 5 & 5 \\
\hline $\mathrm{Ca}\left(\mathrm{NO}_{3}\right)_{2}-\mathrm{mol} \mathrm{L}^{-1}$ & 5 & & 5 & 5 & & 4 & 4 & 5 & 5 & 5 & 5 & 5 & 5 \\
\hline $\mathrm{MgSO}_{4}-\mathrm{mol} \mathrm{L}^{-1}$ & 2 & 2 & 2 & 2 & 2 & & & 2 & 2 & 2 & 2 & 2 & 2 \\
\hline $\mathrm{KCl}-\mathrm{mol} \mathrm{L}_{-1}$ & & 5 & 1 & & & 2 & 2 & & & & & & \\
\hline $\mathrm{CaCl}_{2}-\mathrm{mol} \mathrm{L}^{-1}$ & & 5 & & & & 1 & 1 & & & & & & \\
\hline $\mathrm{NH}_{4} \mathrm{H}_{2} \mathrm{PO}_{4}-\mathrm{mol} \mathrm{L}^{-1}$ & & & & 1 & & & & & & & & & \\
\hline $\mathrm{NH}_{4} \mathrm{NO}_{3}-\mathrm{mol} \mathrm{L}^{-1}$ & & & & 2 & 5 & & & & & & & & \\
\hline$\left(\mathrm{NH}_{4}\right)_{2} \mathrm{SO}_{4}-\mathrm{mol} \mathrm{L}^{-1}$ & & & & & & 2 & & & & & & & \\
\hline $\mathrm{Mg}\left(\mathrm{NO}_{3}\right)_{2}-\mathrm{mol} \mathrm{L}^{-1}$ & & & & & & & 2 & & & & & & \\
\hline Micro - Fe* & 1 & 1 & 1 & 1 & 1 & 1 & 1 & 1 & 1 & 1 & 1 & 1 & 1 \\
\hline Micro - B & & & & & & & & & 1 & & & & \\
\hline Micro- Cu & & & & & & & & & & 1 & & & \\
\hline Micro - Mn & & & & & & & & & & & 1 & & \\
\hline Micro - Zn & & & & & & & & & & & & 1 & \\
\hline Micro - Mo & & & & & & & & & & & & & 1 \\
\hline Fe-EDTA** & 1 & 1 & 1 & 1 & 1 & 1 & 1 & & 1 & 1 & 1 & 1 & 1 \\
\hline
\end{tabular}

* Sarruge (1975); ** Jacobson (1951) 
amarelada das folhas está associada com a menor produção de clorofila e com modificações na forma de cloroplastos (Epstein, 1975; Malavolta, 1980; Raij, 1991)

\section{Fósforo}

Constatou-se que a omissão do fósforo limitou o crescimento da planta, reduzindo o tamanho das folhas novas, levando as folhas mais velhas a apresentarem coloração amarelada, seguida de necrose e secamento das pontas. As folhas mais novas apresentaram coloração verde opaco e ficaram levemente murchas (Fig. 1). Esses sintomas concordam, em parte, com os descritos por La Torraca et al. (1984). Os autores observaram apenas estagnação no crescimento das plantas, em confronto com as plantas submetidas ao tratamento completo, não havendo outros sintomas evidentes. De acordo com Malavolta (1980) e Marschner (1999), a rápida redistribuição do fósforo dos órgãos mais velhos para os mais novos, quando ocorre a carência do elemento, faz com que as folhas mais velhas sejam as primeiras a mostrar os sintomas, ou seja, a carência deste elemento no substrato induz a planta a utilizar o fósforo não metabolizado, localizado no vacúolo das folhas mais velhas, sendo redistribuído para os órgãos mais novos cujo crescimento cessa quando acaba tal reserva.

\section{Potássio}

Plantas vegetando em solução nutritiva na qual o potássio foi omitido apresentaram inicialmente clorose, seguida de necrose das pontas e margens das folhas mais velhas. Esta sintomatologia progrediu com o decorrer da deficiência, até atingir as folhas intermediárias, com as mais velhas secando a partir das pontas, no sentido da ráquis (Fig. 1). O quadro sintomatológico descrito concorda com o observado por La Torraca et al. (1984). Os sintomas de carência de K se manifestam, em primeiro lugar, nas folhas mais velhas (indicação da rapidez na redistribuição), como clorose seguida de necrose das pontas e margens. Nas regiões lesadas (clorose e necrose) acumula-se o tetrametileno diamina ou putrescina, $\mathrm{NH}_{2}\left(\mathrm{CH}_{2}\right)_{4}$ (Malavolta, 1980; Raij, 1991).

\section{Cálcio}

Mudas de pupunheira cultivadas em solução nutritiva, com omissão de cálcio, apresentaram as folhas mais novas "pregueadas", mostrando crescimento desigual, do qual resultou em formas tortas com um gancho na ponta (Fig. 1). La Torraca et al. (1984) relataram, como sintomas iniciais de carência, folhas mais velhas com uma coloração verde clara e onduladas, e notaram ausência de espinhos na lâmina foliar, o que não foi verificado neste trabalho. $\mathrm{O}$ cálcio é absorvido pelas raízes como $\mathrm{Ca}^{+2}$ e o seu movimento ascendente se dá através de reações de troca em vasos condutores, mais do que por fluxo de massa. Depois de localizado nas folhas o Ca se torna imóvel. A falta de cálcio afeta particularmente os pontos de 
crescimento da raiz; aparecem núcleos poliplóides, células binucleadas, núcleos constritos, divisões amitóticas; cessa o desenvolvimento, há escurecimento e morte (Epstein, 1975; Malavolta, 1980).

\section{Magnésio}

Plantas submetidas a tratamento com omissão de magnésio apresentaram, inicialmente, clorose internerval nas folhas mais velhas. Esta sintomatologia, com o decorrer do tempo, transferiu-se para as folhas intermediárias, com as mais velhas tornando-se esbranquiçadas. Esta coloração das folhas está associada com a menor produção de clorofila (Fig. 1). A sintomatologia descrita concorda com a observada por La Torraca et al. (1984). Malavolta (1980) e Marschner (1999) relatam que a absorção do magnésio pelas plantas se faz na forma de $\mathrm{Mg}^{+2}$. O $\mathrm{Mg}^{+2}$, como o $\mathrm{Ca}^{+2}$ e o $\mathrm{K}^{+}$, se move para cima na corrente transpiratória. De modo semelhante ao que ocorre com o potássio, o $\mathrm{Mg}^{+2}$ é móvel no floema e, portanto, os sintomas de carência, clorose internerval, começam nas folhas mais velhas.

\section{Enxofre}

Os sintomas de deficiência de enxofre nas mudas de pupunheira manifestaram-se primeiro com clorose nas folhas mais novas, seguido de enrolamento das margens de todas as folhas (Fig. 1). A sintomatologia descrita diverge da descrita por La Torraca et al. (1984), que observaram a perda da coloração verde característica na ponta das folhas mais velhas e substituição da coloração verde das folhas mais novas por uma coloração verde claro. De acordo com Malavolta (1980) e Raij (1991), a forma de $S$ predominantemente absorvida da solução do solo pela raízes é a altamente oxidada - o sulfato. O sulfato é transportado predomi-nantemente na direção acrópeta, da base da planta para cima; a capacidade da planta para mover o enxofre na direção basípeta é muito pequena; em caso de carência de enxofre os sintomas aparecem em primeiro lugar nos órgãos mais novos, como as folhas mais novas. Os sintomas assemelham-se um pouco com os da deficiência de nitrogênio, mas o enxofre não se transloca das folhas velhas para as novas.

\section{Ferro}

Os sintomas de deficiência de ferro observados no presente estudo ocorreram três meses após o transplantio. Com a falta do elemento, o mais ostensivo sintoma que a planta apresentou foi a alteração na coloração das folhas mais novas; essas folhas exibiram as nervuras bem pronunciadas na tonalidade verde, formando um contraste nítido com o resto amarelo do limbo; a queda gradativa dos níveis de clorofila estampou folhas totalmente cloróticas e mais tarde esbranquiçadas. A segunda e a terceira folhas após a flecha apresentavam também uma forma pontiaguda e mais estreita, comparadas com folhas normais (Fig. 1). A sintomatologia descrita está de 
acordo com a observada por Salvador et al. (1997) para mudas de goiabeira e por Martins et al. (2000) em mudas de andiroba (Carapa guianensis Aub1.). Segundo alguns autores (Epstein, 1975; Malavolta, 1980; Raij, 1991), o transporte do ferro se dá na corrente transpiratória e, no exsudado do xilema, o ferro aparece largamente como quelado do ácido cítrico. $\mathrm{Na}$ planta em desenvolvimento e na adulta, entretanto, não se dá praticamente a redistribuição do $\mathrm{Fe} e$, como consequiência, a lâmina foliar amarelece, enquanto as nervuras podem ficar verdes durante algum tempo, destacando-se como um reticulado muito fino. Em casos extremos, as folhas adquirem coloração esbranquiçada.

\section{Boro}

Observou-se que os sintomas decorrentes da deficiência de boro em mudas de pupunheira manifestaram-se nas folhas mais novas, que ao se desenvolverem mostravam ondulações na lâmina foliar (Fig. 1). Este resultado diverge do obtido por La Torraca et al. (1984) que observaram, como sintomas iniciais nas folhas mais velhas uma coloração verde mais intensa, e nas folhas novas quando surgiam não se desenrolavam e quando isto ocorria mostravam falhas no limbo, o que não foi comprovado neste trabalho. O B mostra transporte unidirecional no xilema, na corrente transpiratória e grande imobilidade no floema, características que reparte com o Ca. A falta de redistribuição do boro tem as seguintes conseqüências: (1) os sintomas de carência aparecem primeiramente nos órgãos mais novos e regiões de crescimento (redução no tamanho e deformação das folhas mais novas, morte da gema terminal, menor crescimento das raízes); (2) a planta necessita de um suprimento contínuo para viver (Epstein, 1975; Malavolta, 1980).

\section{Zinco}

Os sintomas visuais de deficiência deste nutriente manifestaram-se, inicialmente, nas folhas mais novas, as quais apresentaram-se amareladas, estreitas, alongadas em forma de lanças e com necrose bastante evidente nas pontas, se expandindo em direção a ráquis. Notou-se também que a flecha já apresentava secamento nas pontas, mostrando claramente a morte de todo o tecido (Fig. 1). Estes sintomas são semelhantes aos descritos por Martins et al. (2000) em mudas de andiroba (Carapa guianensis Aubl.). De acordo com Malavolta (1980) e Marschner (1999), o zinco é um elemento pouco móvel na planta, particularmente nas mais deficientes e nas folhas velhas. Os sintomas mais típicos de carência de zinco consiste no encurtamento dos internódios e na diminuição da produção de folhas novas, que tornam-se pequenas, cloróticas e lanceoladas; podem aparecer tonalidades roxas nos caules e nas folhas.

Não foram constatados sintomas visuais que caracterizassem as deficiências de cobre, manganês e molibdênio. Uma das possíveis causas que não permitiu que o $\mathrm{Cu}, \mathrm{Mn}$ e $\mathrm{Mo}$ atingissem níveis de carência, manifestando sintomas visuais, pode 

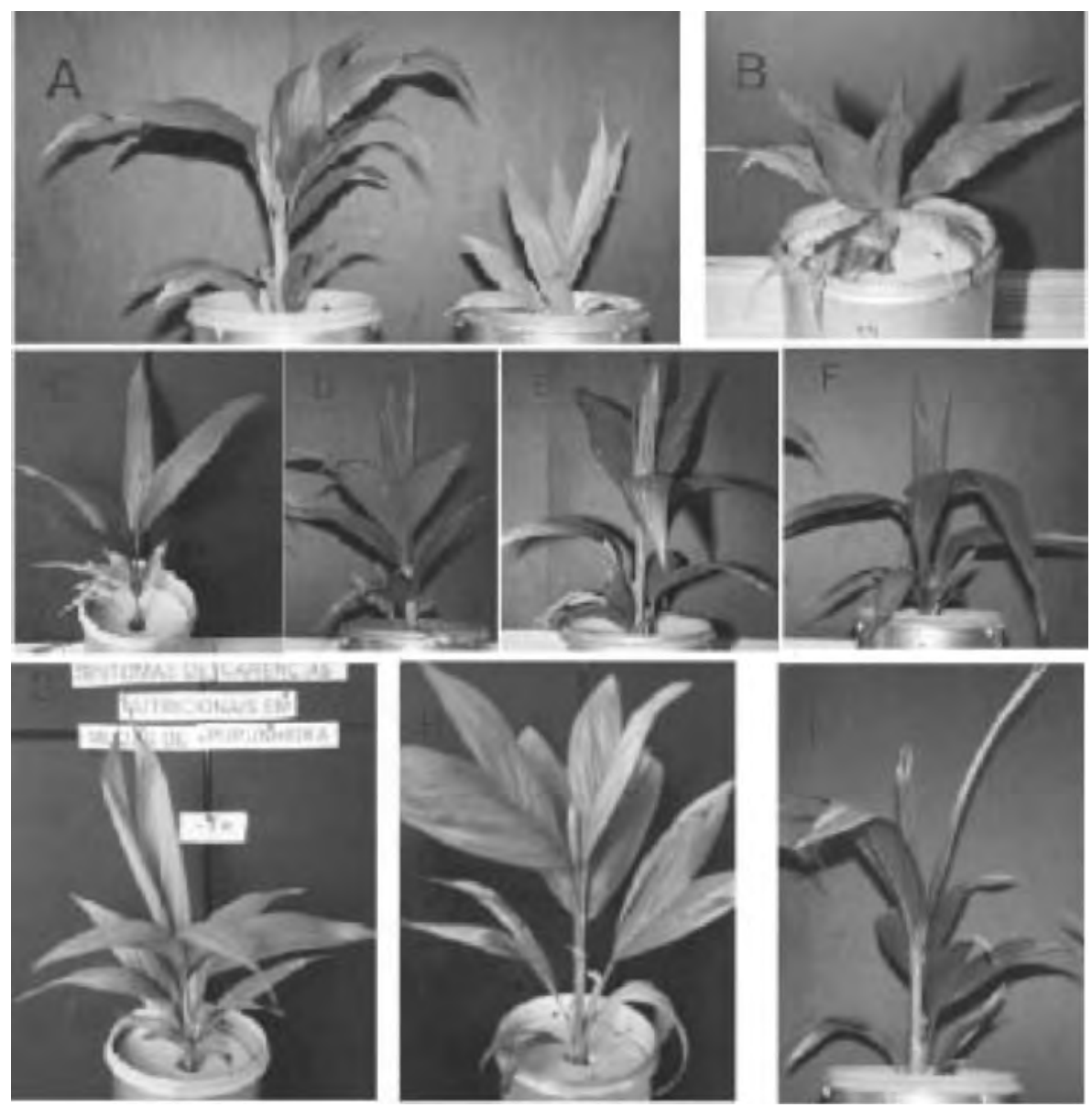

Figura 1 - Sintomas de deficiências de nutrientes em mudas de pupunhas: a) nitrogênio; b) fósforo; c) potássio, d) cálcio; e) magnésio; f) enxofre; g) ferro; h) boro e i) zinco

ser a baixa exigência desta cultura, tendo sido suficientes as quantidades desses elementos fornecidas na solução completa diluída antes da instalação dos tratamentos de omissão.

Um outro fator que pode ter contribuído para isso foi a utilização de fontes de nutrientes de baixa pureza química que podem ter introduzido contaminantes nas soluções. Segundo Novais et al. (1991), o problema maior associado aos contaminantes diz respeito aos elementos existentes em baixas concentrações na solução; os micronutrientes, pois quando se deseja avaliar os efeitos da carência extrema - ausência - de certo micronutriente sobre a sintomatologia apresentada por uma planta, é essencial que as fontes dos vários nutrientes, constituintes das soluções nutritivas, sejam de elevado grau de pureza. Fontes (1986) afirma também que além dos produtos químicos usados para o fornecimento de nutrientes às soluções, outras fontes potenciais de 
contaminação são a água, os recipientes e outros materiais utilizados no preparo de soluções, além do substrato usado para germinação, emergência e início de crescimento das plântulas.

\section{Niveis analíticos}

A sintomatologia visual das carências foi confirmada por análise química das plantas conforme se observa na Tabela 2. As concentrações de nutrientes na parte aérea das plantas submetidas ao tratamento completo obedeceram a seguinte ordem decrescente: $\mathrm{N}>\mathrm{K}>\mathrm{Ca}>\mathrm{Mg}>\mathrm{P}>$ $\mathrm{Fe}>\mathrm{Zn}$. Este resultado coincide com o obtido por Herrera (1989) em um plantio de pupunheira para produção de palmito na Costa Rica. O autor mencionou também que o nitrogênio é o elemento removido em maior quantidade pela planta, seguido pelo potássio.

$O$ teor de nitrogênio observado nas folhas das plantas sob tratamento completo (Tab. 2) situou-se na faixa dos valores adequados observados pela maioria dos autores (La Torraca et al., 1984; Molina, 1997; EMBRAPA, 1999). O teor de nitrogênio nas plantas submetidas a tratamento com omissão deste nutriente foi inferior ao encontrado em plantas com deficiência por La Torraca et al. (1984).

Notou-se que o teor de fósforo nas plantas submetidas a tratamento com solução nutritiva completa foi superior aos encontrados por alguns autores (La Torraca et al., 1984; Molina, 1997; EMBRAPA, 1999) em folhas de plantas sadias (Tabela 2). $\mathrm{O}$ nível de fósforo encontrado nas plantas deficientes, neste tratamento, superou o valor encontrado por $\mathrm{La}$ Torraca et al. (1984) em plantas com deficiência.

A concentração de potássio observada nas plantas sadias (Tab. 2) foi semelhante ao valor observado por La Torraca et al. (1984), no entanto, ficou bem acima dos níveis considerados como adequados por Molina (1997) e EMBRAPA (1999). O teor de potássio encontrado nas plantas com deficiência foi inferior ao encontrado em plantas deficientes por La Torraca et al. (1984).

O teor de cálcio encontrado nas plantas submetidas a tratamento completo (Tab. 2) foi comparável ao encontrado por La Torraca et al. (1984), no entanto, foi superior a faixa de teores considerados como adequados por Molina (1997) e EMBRAPA (1999). Para as plantas deficientes, o nível de cálcio encontrado foi menor do que o verificado por La Torraca et al. (1984) em plantas com carência nesse nutriente.

Observou-se que o teor de magnésio encontrado nas plantas sob tratamento com solução nutritiva completa foi inferior ao detectado por La Torraca et al. (1984), entretanto, encontra-se dentro da faixa de teores adequados citados pela EMBRAPA (1999) e superior a indicada por Molina (1997) (Tab. 2). O nível de magnésio nas plantas com deficiência nesse nutriente foi inferior ao observado por La Torraca et al. (1984) 
Tabela 2. Teores foliares de macro e micronutrientes considerados adequados para pupunheira (análises de folhas), e resultados de ensaios comparando teores de nutrientes em folhas de pupunheira, submetidas a tratamento completo e deficientes.

\begin{tabular}{|c|c|c|c|c|c|c|}
\hline \multirow[t]{2}{*}{$\begin{array}{c}\text { Nutrientes } \\
\text { Macronutrientes (g kg-1) }\end{array}$} & \multicolumn{6}{|c|}{ Concentração foliar } \\
\hline & Adequados 1 & Adequados ${ }^{2}$ & Completo $^{3}$ & Deficiente $^{3}$ & Completo $^{4}$ & Deficiente $^{4}$ \\
\hline $\mathrm{N}$ & $25-40$ & $22 \cdot 35$ & 27,6 & 14,4 & 30,7 & 10,1 \\
\hline $\mathrm{P}$ & $1,5-3,0$ & $2,0-3,0$ & 2,3 & 0,6 & 3,4 & 1,0 \\
\hline $\mathrm{K}$ & $8-15$ & $9-15$ & 30,2 & 10,3 & 27,8 & 4,7 \\
\hline $\mathrm{Ca}$ & $2,0 \cdot 5,0$ & $2,5-4,0$ & 14,3 & 3,3 & 12,7 & 2,6 \\
\hline $\mathrm{Mg}$ & $2,0-3,0$ & $2,0-4,5$ & 4,6 & 2,0 & 3,5 & 0,9 \\
\hline \multicolumn{7}{|l|}{ Micronutrientes (mg kg- $\left.{ }^{-1}\right)$} \\
\hline $\mathrm{Fe}$ & $100-200$ & $40-200$ & & & 175 & 191 \\
\hline $\mathrm{Zn}$ & $15 \cdot 25$ & $15-40$ & & & 33,0 & 41,0 \\
\hline
\end{tabular}

(1) Molina (1997); (2) EMBRAPA (1999); (3) La Torraca et al. (1984); ${ }^{(4)}$ Resultados deste trabalho

em plantas deficientes.

Na Tabela 2 pode-se constatar também que os tratamentos deficientes acusam teores bem inferiores aos do tratamento completo, com exceção do ferro e do zinco. No entanto, segundo Malavolta (1980), o teor de ferro total e zinco em folhas de plantas deficientes pode ser mais alto (ou pelo menos igual) ao encontrado em folhas de plantas normais.

\section{Conclusões}

A falta, individualizada, de N, $\mathrm{P}$, $\mathrm{K}, \mathrm{Ca}, \mathrm{Mg}, \mathrm{S}, \mathrm{B}, \mathrm{Fe}$ e $\mathrm{Zn}$ na solução nutritiva produziu alterações morfológicas, traduzidas como sintomas característicos de deficiência nutricional para cada elemento estudado. Todas as deficiências obtidas produziram profundas modificações no desenvolvimento da pupunheira na sua fase inicial. Não se detectou sintomas de carência de $\mathrm{Cu}$, Mn e Mo, provavelmente por alguma contaminação. Os teores dos nutrientes encontrados nas folhas do tratamento completo e com omissão foram respectivamente: $\mathrm{N}\left(\mathrm{g} \mathrm{kg}^{-1}\right) 30.7$ 10.1; P ( $\left.\mathrm{g} \mathrm{kg}^{-1}\right) 3.4$ - 1.0; $\mathrm{K}\left(\mathrm{g} \mathrm{kg}^{-1}\right)$ 27.8 - 4.7; Ca $\left(\mathrm{g} \mathrm{kg}^{-1}\right) 12.7$ - 2.6; $\mathrm{Mg}$ $\left(\mathrm{g} \mathrm{kg}^{-1}\right) 3.5$ - 0.9; Fe (mg kg-1) 175 191; Zn (mg kg-1) 33 - 41.

\section{Bibliografia citada}

Arkcoll, D.B.; Aguiar, J.P.L. 1984. Peach palm (Bactris gasipaes H.B.K.) a new source of vegetable oil from the wet tropics. J. Sci. Food Agric., 35(5):520-526.

Clement, C.R.; Mora Urpí, J. 1987. Pejibaye palm (Bactris gasipaes, Arecaceae): multiuse potential for the lowlad humid tropics. Econ. Bot., 41(2):302-311.

EMBRAPA. 1999. Manual de análises químicas de solos, plantas e fertilizantes. Embrapa, Brasília. 370p.

Epstein, F. 1975. Nutrição mineral das plantas; princípios e perspectivas. Editora da Universidade de São Paulo, São Paulo. 341p.

Fontes, R.L.F. 1986. Purificação de solução nutritiva para indução de deficiências de zinco e cobre em plantas. Tese Mestrado, Universidade Federal de Viçosa, Viçosa. $72 \mathrm{p}$. 
Herrera, W. 1989. Fertilización del pejibaye para palmito. Boletín Pejibaye (Guilielma) Serie Técnica (Universidade de Costa Rica, San José) 1(2):4-10.

Jacobson, L. 1951. Maintenance of iron supply in nutrient solutions by a single addition of ferric potassium ethylene-diaminetetra-acetate. Plant Physiol., 26:410-411.

La Torraca, S.M.; Haag, H.P.; Dechen, A.R. 1984. Nutrição mineral de frutíferas tropicais I. Sintomas de carências nutricionais em pupunha. O Solo, 76(1): 53-56.

Lopes, A.S. 1989. Manual de fertilidade do solo. ANDA/POTAFOS, São Paulo. 155p.

Malavolta, E. 1980. Elementos de nutrição mineral de plantas. Edição Ceres, São Paulo. 251p.

Malavolta, E.; Vitti, G.C.; Oliveira, S.A. 1989. Avaliação do estado nutricional das plantas: princípios e aplicações. Associação Brasileira para Pesquisa da Potassa e do Fosfato, Piracicaba. 201p.

Marschner, H. 1999. Mineral nutrition of higher plants. Academic Press, London. $889 \mathrm{p}$.

Martins, G.C.; Mellone, R.; Carvalho, J.G. 2000. Efeito da omissão de micronutrientes no crescimento de mudas de andiroba (Carapa guianensis Aubl.). In: Anais do XXV Reunião Brasileira de Fertilidade do Solo e Nutrição de Plantas, Fertbio 2000 (CD-ROM). Universidade Federal de Santa Maria, Santa Maria, RS. 3p.

Molina, E. 1997. Fertilización y nutrición de pejibaye para palmito. Research report, Centro de Investigaciones Agronómicas. Universidade de Costa Rica, San José. 26p.

Mora Urpí, J. 1984. E1 pejibaye (Bactris gasipaes H.B.K.): origem, biología floral y manejo agronómico. In: Palmeras poco utilizadas de América Tropical. CATIE, Turrialba, Costa Rica. pp. 118-160.

Novais, R.F.; Neves, J.C.L.; Barros, N.F. 1991. Ensaio em ambiente controlado. In: Oliveira, A.J.; Garrido, W.E.; Araújo, J.D.; Lourenço, S. (Eds.). Métodos de pesquisa em fertilidade do solo. EMBRAPA-SEA,
Brasília, DF. pp.189-255.

Raij, B. 1991. Fertilidade do solo e adubação. Agronômica Ceres, São Paulo. 343p.

Salvador, J.O.; Moreira, A; Muraoka, T. 1997. Sintomatologia de deficiências de micronutrientes em mudas de goiabeira. In: Anais do XXVI Congresso Brasileiro de Ciência do Solo (CD-ROM). Sociedade Brasileira de Ciência do Solo, Rio de Janeiro, RJ. 3p.

Sarruge, J.R. 1975. Soluções nutritivas. Summa Phytopatologica, 1(3): 213-233.

Sarruge, J.R.; Haag, H.P. 1974. Análises químicas em plantas. ESALQ, Departamento de Química, Piracicaba. 56p.

Aceito para publicação em 04/09/2002. 
